\title{
The Distinction and Relationship between Ontology and Epistemology:
}

\author{
Does It Matter?
}

\section{Sarita-Louise Kant}

Sarita-Louise Kant of Pretoria received her Bachelor of Arts degree in the Humanities (Politics) at the University of South Africa in 1979. In 1989, she obtained a Master of Arts degree at the University of South Africa. The dissertation was entitled 'Ayn Rand's contribution to political thought. An evaluation'. The dissertation was passed 'cum laude'. She obtained her doctorate (D Litt et Phil) in 2010 at the University of South Africa. The thesis was entitled 'A critical and systematic analysis of the democratic values of freedom and equality'. Fields of interest include issues in the philosopby of science and political philosophy.

\begin{abstract}
In the social sciences, a distinction is generally drawn between ontology and epistemology, usually accompanied by the assumption that some relationship exists between ontology and epistemology. In this regard several issues arise. Whereas there seems to be general agreement on the meaning of the concepts 'ontology' and 'epistemology', there seems to be no agreement on what can be classified as ontological or epistemological. The distinction and particularly the relationship between ontology and epistemology is furthermore regarded by some scholars as problematic and contested. The aim is to examine the distinction and the presumed nature of this relationship in order to establish why it is contested. It is extremely important to take cognisance of the possibility of fallacious reasoning concerning the distinction and the relationship between ontology and epistemology, as the failure to do so may have serious consequences for the integrity and validity of research projects in the social sciences. Lastly, it is also relevant to determine whether the distinction and the presumed relationship between ontology and epistemology are important for the scientific enterprise.
\end{abstract}

Keywords: Epistemology; Category Mistake; Fallacy; Ontology; Solipsism. 


\section{Introduction}

In postmodern times in the social sciences, it is common practice to misuse and abuse concepts like 'ontology' and 'epistemology' and their meanings by using them interchangeably or by collapsing the distinction between them, and to overlook and sometimes ignore the rules of language and logic, thereby enhancing the possibility of fallacious reasoning. This practice has serious consequences for the validity and soundness of research projects in the social sciences. Validity does not seem to be a concern of postmodern discourse and its presumed concomitant epistemology, which differs radically from, for example, a realist as well as a positivist epistemology.

Consequently, after having clarified the meaning of the concepts of ontology and epistemology, and determined their scope, the presumed relationship between ontology and epistemology will be examined. Some of the arguments concerning the relationship and the distinction between ontology and epistemology will be analysed to examine the possibility of whether fallacious thinking is involved. Lastly, an attempt will be made to establish whether the distinction and the relationship between ontology and epistemology are important for research in the social sciences. The approach followed here is critical with regard to the points of view provided by various scholars.

\section{The Meaning of Ontology and Epistemology and the Distinction between Them}

Furlong and Marsh (Marsh and Stoker 2010: 185) affirm that there is general agreement on the meaning of ontology and epistemology. The general agreement is also evident from the ensuing views expressed by scholars.

Ontology is a branch of metaphysics. Metaphysics has various different meanings. It can refer to the study of reality or existence as a whole, or particular aspects of reality, for instance, monism (reality consists of one substance) or monadology (reality consists of many substances). Metaphysics also explores the world beyond experience in order to establish first principles as the foundation of knowledge. It also examines the kinds of things that ultimately exist (Flew 1984: 229-230). However, in this context metaphysics refers to the study of reality as a whole. Ontology then is concerned with the nature of reality or existence, which is "apart from the nature of any existent object" (Flew 1984: 255; see Blaikie 2007: 13). It addresses the question of "what is out there to know about" (Grix 2002: 1). In the social sciences ontologies concern the question: "What is the nature of social reality?" (Blaikie 2007:13). The forgoing implies the 
existence of a reality independent of human beings' knowledge of it, which will be analysed further on.

Epistemology studies theories of knowledge, how knowledge is derived (for instance, by reason or experience, which may both take various forms), and the reliability and validity of knowledge claims (Flew 1984: 109; see Grix 2002: 177).

Ontological questions focus on the nature of reality. Put differently, the key issue is "whether there is a "real" world "'out there" that is ... independent of our knowledge of it" (Furlong and Marsh in Marsh and Stoker 2010: 185). If this view is upheld, the basic epistemological question concerns "the nature of the relationship between the knower and what can be known" (Furlong and Marsh in Marsh and Stoker 2010: 185).

Marsh and Stoker (2002: 11) follow a similar view and depict ontology and epistemology as follows: "ontology is concerned with what we can know about the world and epistemology is concerned with how we can know it"'. Although Marsh and Stoker clearly distinguish between ontology and epistemology, Bates and Jenkins (2007: 58) find their description problematic and incorrect as in their view what exists is an ontological issue which is not the same as the epistemological issue of what we can know.

Nevertheless, Grix (2002: 175) concurs with Marsh and Stoker (2002: 11) when he asserts that ontology means "what is out there to know about" and epistemology refers to "what and how can we know about it". Here a clear distinction is again drawn between ontology and epistemology. Furthermore, Hay (2002: 63 in Grix 2002: 177) states that a researcher's ontological position is reflected in the answer to the question of "what is the nature of the social and political reality to be investigated?"'. This question must be answered before one can consider what one can know about this social and political reality (Grix 2002: 177). What one can know about reality is an epistemological question.

Moses and Knutsen (2007: 5) is similarly of the view that ontology refers "to the study of being the study of the basic building blocks of existence". Epistemology accordingly denotes the study of knowledge. The basic question is "' $[w]$ hat is knowledge”' (Moses and Knutsen 2007: 5).

Furlong and Marsh (Marsh and Stoker 2010: 185) follow a realist perspective to demonstrate the link between ontology and epistemology. Accordingly, epistemology concerns two main questions. The first one relates to the issue whether an observer or researcher can identify 
objective or real relations between social phenomena. The first question entails a return to ontology, that is, whether reality exists independent of the observer or researcher.

The second question concerns how the researcher can identify real relations between social phenomena, if the first question in answered affirmatively. Negating the existence of an independent reality means that no researcher can be objective as the social world or reality is socially constructed (Furlong and Marsh in Marsh and Stoker 2010: 185). The second question, furthermore, raises an important and related issue of whether a researcher can establish real relations between phenomena by means of direct or indirect observation. The answers to all these questions influence a researcher's epistemological position (Furlong and Marsh in Marsh and Stoker 2010: 186).

Scholars who follow variants of realism draw a clear distinction between ontology and epistemology. The distinction and link between ontology and epistemology, as expounded, for example, by Furlong and Marsh is regarded as contentious, particularly by researchers favouring a constructivist perspective for conducting research in the social sciences. Constructivists are apt to reject the distinction between ontology and epistemology. Nevertheless, it should be borne in mind that the commonsensical distinction between ontology and epistemology is one matter, and whether this distinction is accepted or rejected by scholars is another.

\section{Classification of Ontological and Epistemological Positions}

Whereas there is general agreement on the meaning of the terms ontology and epistemology, there is "much less agreement about either the ontological and epistemological positions that researchers adopt or the relationship between ontology and epistemology" (Furlong and Marsh in Marsh and Stoker 2010: 185).

Blaikie (2007: 13) distinguishes between idealist and realist ontological assumptions. Idealism assumes that "the external world is just appearances and has no independent existence apart from our thoughts" and realism holds that "both natural and social phenomena are assumed to have an existence that is independent of the activities of the human observer" (Blaikie 2007: 13). More recently though a distinction is drawn between realist and relativist ontologies, both of which have many variations (Blaikie 2007: 13). The variations of realism, for example, which include scientific realism and critical realism, despite their differences, subscribe to the existence of a mind independent reality. 
As far as epistemological positions are concerned, two alternatives were traditionally regarded as "the foundations of knowledge", namely, rationalism and empiricism. Rationalism takes reason as a source of knowledge, "to distinguish between what is true and false" (Blaikie 2007: 18). Empiricism in contrast bases knowledge of reality on sensory experience (Blaikie 2007: 18).

In order to further clarify the distinction between ontology and epistemology, Furlong and Marsh (Marsh and Stoker 2010: 185) demonstrate the complexity of ontological positions by identifying two main ontological ones, namely, "foundationalism/objectivism/realism" which supports an external world, independent of people's knowledge of it, and "antifoundationalism/constructivism/relativism" which views the world as a socially constructed entity. These two streams, however, have different variations and the distinctions between them may be obfuscated (Furlong and Marsh in Marsh and Stoker 2010: 189).

The use of the terms "foundationalism" and "'anti-foundationalism" as ontological terms are regarded by Bates and Jenkins (2007: 58) as a "conflation of ontological and epistemological concerns". These terms are not ontological but rather epistemological (Bates and Jenkins 2007: 59).

Furlong and Marsh (Marsh and Stoker 2010: 185), however, clearly distinguish between a researcher's ontological and epistemological positions, which is also indicative of the interrelationship between ontology and epistemology: "If an ontological position reflects the researcher's view about the nature of the world, his or her epistemological position reflects his/her view of what we can know about the world...". Furthermore, the main epistemological question concerns "the nature of the relationship between the knower and what can be known..." (Furlong and Marsh in Marsh and Stoker 2010:185).

Grix (2002: 177-178) refers to Bryman's (2001: 12-13, 16-18) examples of "'objectivism" and "constructivism" as ontological positions, and "positivism" and "interpretivism" as epistemological positions. Objectivism as an ontological stance states that social entities and their meanings exist independently of human beings. Constructivism holds that social phenomena are socially constructed and subject to revision by observers or researchers. Positivism, as an epistemological position, applies the methods of the natural sciences to the social sciences. Interpretivism again distinguishes between the methods of the natural sciences and those methods applicable to the social sciences. The methods of the social sciences are regarded as subjective in nature. Similarly, Furlong and Marsh (Marsh and Stoker 2010: 185) identify interpretivism as an epistemological position. 
Jackson (2008: 132-133) again identifies dualism and monism as ontological positions. Dualism makes a strict distinction "between the world and knowledge of the world, whether that knowledge is held by the researcher or by the people under investigation" (Jackson 2008: 132). Knowledge is regarded as a representation of the world. Knowledge is derived from and refers to "a world of objects that exist and have their character outside of any knowledge" (Jackson 2008: 132; see Flew 1984: 97). Monism, on the other hand, "maintains a fundamental continuity of knowledge with the world, and therefore does not give rise to an account of knowledge practices that aims at accurately reflecting the world's essential dispositional character" (Jackson 2008: 133; see Flew 1984: 237).

Whereas idealism entails a world constructed by the researcher's thoughts, monism "avoids the thing/thought dichotomy altogether" and focuses on practical activities that lead to both objects and thoughts, which may be called "discursive practices, fields of action, figurations" and so forth (Jackson 2008: 133). Monists deny that human beings can obtain knowledge of the world as it exists. It is clear that adhering to either monist or dualist ontological assumptions leads to practicing different kinds of social science (Jackson 2008: 133).

It is evident that there is less agreement among scholars on ontological and epistemological positions and classifications, and the positions that researchers support (see Furlong and Marsh in Marsh and Stoker 2010: 185).

\section{The Distinction and Relationship between Ontology and Epistemology}

Whereas the meaning of ontology and epistemology is generally accepted, the distinction and the relationship between ontology and epistemology, particularly in postmodern times, are contentious and contested, especially by interpretivists, constructivists and scholars of hermeneutics (see further on).

The relationship has several disputed facets: the directionality of the relationship between ontology and epistemology; the distinction between ontology and epistemology, (albeit its denial); conflating or collapsing the distinction between ontology and epistemology, which tends to reduce the former to the latter; and the ontological issue of the existence of an external, mind independent reality, whether social or political, which can be studied by observers or researchers. These points will be briefly examined.

There are views for and against indicating the directional relationship between ontology and epistemology. 
Grix (2002) asserts that ontology logically precedes epistemology and that both are logically closely related. The nature of the relationship is logical. Hay (2007: 116-117) concurs and supports the "primacy of ontology over epistemology". Ontological claims about the social and political world logically precede epistemological claims concerning what can be known about that social and political world. Hence, epistemology is dependent on ontology. This position, however, is a matter of logic and not of metatheory. Hay (2007: 118) further contends that "ontological assumptions inform epistemological assumptions" and that "both inform methodological choices".

Some scholars in the social sciences again hold that epistemology precedes ontology, but the grounds for this and the defence of this position are not clear in the literature. Scholars and researchers who do not present some argument for their positions cast some doubt on the validity of their views. It must be noted that a valid defence first and foremost requires "a clear statement of the strongest arguments of your opponent as a preliminary to their refutation" (Lunn 1950: vii). This requirement is fundamental to research in the social sciences as well as arguments in philosophy.

Bates and Jenkins (2007: 56) are against what they regard as "a tendency to present, indeed prescribe, a particular directional relationship between ontology and epistemology as a given...”. Prescribing a directional relationship undermines "reflexive learning and the development of critical analysis...” (Bates and Jenkins 2007: 56).

However, Bates and Jenkins (2007: 60) do not argue that directionality is incorrect, but stress that this perspective is contested (see Marsh and Stoker 2010: 186). Some views perceive the relationship between ontology and epistemology differently. For instance, neither ontology nor epistemology can be seen as prior to the other. Another perspective bases ontology on epistemology. Yet another view collapses the distinction between ontology and epistemology. For Grix (2007: 179) this means that ontology is simply seen as a part of epistemology.

Hay (2007: 117) acknowledges that some scholars confuse and conflate ontology and epistemology. Bates and Jenkins (2007: 60) affirm that some post-structuralists conflate ontology and epistemology. According to Furlong and Marsh (Marsh and Stoker 2010: 189) poststructuralist scholars deny the possibility or usefulness of a distinction between ontology and epistemology.

Some scholars writing within the ambit of hermeneutics are also inclined to confuse ontology and epistemology. Understanding society, which is different from nature, requires "an 
interpretive understanding of society where we try and grasp other's thoughts with our thoughts" (Spencer 2000: 2). This tends to reduce the study of society to the understanding of thoughts on the issue (see point 5.1 further on).

Hermeneutics and structuralism emphasise the importance of language and oppose "attempts at explaining human society in terms of human nature" (Trigg 1985: 188-189). This kind of structuralism, furthermore, rejects the notion of human beings as subjects thinking about an independent, external world and formulating a language to describe that world. This means that human beings are neither the source of language, nor of culture (Trigg 1985: 189-190). Language then has some independent status. In other words, language is reified. Reification means regarding "human products as if they were entities independent of man" (Trigg 1985: 211). It is not clear how language can have an independent status as it is the product of a conscious mind or intellect. Language, moreover, is a means of communication and an instrument of knowledge. The social sciences (and natural science) as well as scientific practice depend on the quality of terms and concepts. As Sartori (1984:22) puts it:

Clear thinking requires clear language. In turn, a clear language requires that its terms be explicitly defined.

The existence of an independent natural, social and political world was implicit in much of the forgoing discussion. Realism supports the notion of an independent reality which exists apart from the subject, knower or researcher. However, in postmodern times "it is usual to either deny that reality exists apart from our knowledge (usually understood as our linguistic representations) of it or to deny that our knowledge in any way 'reflects' the world as it exists in and of itself' (Spencer 2000: 1).

Some of the issues concerning the distinction and relationship between ontology and epistemology will be further examined to establish whether or not fallacious thinking is entailed in some of the views expounded above.

\section{The Issue of Fallacious Reasoning}

Two issues concerning ontology and epistemology are particularly important here. The first concerns collapsing the distinction between ontology and epistemology and treating the former as an aspect of the latter. The second issue pertains to the ontological assumption of the existence of an independent social and political reality. 


\section{The distinction between ontology and epistemology}

Does collapsing, conflating or confusing the distinction between ontology and epistemology possibly entail a category mistake? According to Ryle (1988: 17; see Flew 1984: 58) a category mistake is made when a concept or term belonging to "one logical type or category" is placed in another category to which it does not belong. A category mistake depends on some theory of categories. In an Aristotelian sense it refers to “a sort of equivocation” (Flew 1984: 58).

One of several examples given by Ryle (1988: 17-18) to illustrate a category mistake involves a foreigner visiting Oxford or Cambridge University for the first time. The foreigner is shown several colleges, libraries, museums, scientific departments, administrative offices and playing fields. The visitor afterwards asks where the university is. He has seen various institutions, but not the university. The visitor made the mistake of thinking that the university was yet another building instead of the university being the way in which all the buildings and playing fields are organised (Ryle 1988: 18; see Baggini and Fosl 2003: 73-74). The various institutions, buildings and playing fields (observable reality) comprise the whole, the university (an abstraction). These are clearly different categories.

Ryle (1988: 19) states that theoretically the most interesting category mistakes are made by those who are "perfectly competent" to apply terms and concepts in the cases "with which they are familiar, but are still liable in their abstract thinking to allocate those concepts to logical types to which they do not belong”.

As an example of an interesting category mistake, Ryle (1988: 19) tells the story of a student of politics, who has learned the main differences between the French, British and American constitutions, as well as the differences and connections between Parliament, the Cabinet, the Judiciary, the various ministries and the Church of England. When asked questions about the connections between the Church of England, the British constitution and the Home Office, the student still became embarrassed. The Church and the Home Office are institutions, but the British constitution is not just another institution in the same sense as the noun 'institution'. Hence, the relations between institutions which may be claimed or denied to exist between the Church and the Home Office cannot be stated or denied to hold between either of the two institutions and the British constitution. The latter term 'constitution' is not of the same logical type as the Church and the Home Office.

From the above it is clear that concepts and terms belonging to a particular logical category must not be placed in a category to which it does not belong. This means that the distinction between 
ontology and epistemology must not be collapsed. Historically and philosophically the concepts of ontology and epistemology refer to different things. They are not the same and the one must also not be confused with or reduced to the other. Spencer (2000: 1) cites Roy Bashker's notion of an epistemic fallacy which reduces issues of ontology to epistemology. "Hence, the epistemic fallacy would assume that for any question of whether or not such and such exists, we should substitute the question of how we know that such and such exists" (Spencer 2000: 1). What can be observed must not be confused with what is real. Reality consists of more than what can be observed. The two must not be conflated (Chernoff 2007: 121; see Bhasker 1997: 36-38). In this view, the distinction between ontology and epistemology must thus be upheld to avoid the committing of a category mistake.

If ontology and epistemology are conflated, the study of society is then reduced to the understanding of ideas. However, it is correct to see society as a unique entity, as "ideas can be causes" (Spencer 2000: 2). Society is complex and the causes of behaviour, political, social and economic relations and events in society cannot merely be regarded as ideas, or caused by people's ideas. Society cannot logically be reduced to ideas and the study of society cannot logically be reduced to issues of epistemology (Spencer 2000: 2).

Finally, Spencer (2000: 4) emphasises that "[t]he confusion between ontology and epistemology $\ldots$ is the confusion between the study of thought and the study of the world as it exists independently of thought... “.

\section{An independent reality}

In contrast with idealism, which supports the notion that an external reality is not completely independent of mind, (or that the mind somehow creates reality, or that reality is dependent on the observer's beliefs about it, or in the Hegelian sense that material things is a form of one (absolute) mind) (see Flew 1984: 160-161), the existence of an external mind independent reality has philosophically been accepted since the earliest times. Rand (1961: 22) affirms that Aristotle “defined the basic principles of a rational view of existence and of 'human' consciousness: that there is only one reality, the one which man perceives - that it exists as an objective absolute (which means: independently of consciousness, the wishes or the feelings of any perceiver) - that the task of man's consciousness is to perceive, not to create reality ... “.

If the axiom of the "primacy of existence" and the axiom that consciousness perceives reality are rejected then the primacy of consciousness is the alternative or represents a reversal, namely "the notion that the universe has no independent existence, that it is the product of consciousness 
(either human or divine or both)" (Rand 1982: 29). This entails the inability to understand the difference between the outer world and a person's inner state, or between the perceiver and the perceived. Rand (1982: 30) calls this the "fallacy of failing to discriminate crucial differences". This fallacy collapses the distinction between reality, the perceived, and consciousness, the perceiver. Here again, the possibility of a category mistake arises.

Hallowell (1954: 25), who supports the common sense principles of classical realism, also asserts that the existence of reality "does not depend upon our knowledge of it" and that " $[\mathrm{k}]$ nowledge does not involve the making or constructing of anything, but rather the discovery of what already exists".

Scholars and views of science that contend that reality is mind dependent, or deny the existence of an independent reality, also run the risk of committing the well-known fallacy of solipsism, which denies the existence of an external reality. The fallacy of solipsism is described by Flew (1984: 330) as follows:

I must hold that I alone exist independently, and that what I ordinarily call the outside world exists only as an object or content of my consciousness.

On a metaphysical level solipsism holds that 'I alone exist', and in an epistemological sense one can only know oneself and nothing else. Mounce (1977: 11) elaborates on this dilemma:

I cannot say that I alone exist, as against the world, for without the world I cannot distinguish my own existence. Consequently what is true in solipsism cannot be expressed without recognizing the truth in realism. I cannot say that the world appears to me, without recognizing the reality of the world which so appears.

For Stove (1991: 65) even asking the question of whether an external world exists demonstrates that there is something seriously wrong regardless of how the question is answered. Stove (1991: 71) remarks that:

'An external world exists' follows from 'At least one human being exists', just as it follows from, say, 'At least one cabbage exists.' Now, necessarily, no human being could ask, even inwardly, whether an external world exists, unless at least one human being exists. And necessarily, if at least one human being exists then an external world exists. Therefore, necessarily, no human being could ask whether an external world exists, unless an external world does exist. 
The statement concerning the existence of an external world, in other words, follows from any observation statement (Stove 1991: 72). A statement that denies the existence of an external world seems to at least implicitly accept its existence in an attempt to deny it.

Furthermore, something, for example, realism, is not contingent as it has no contingent contrary. The statement on the existence of an external world does not seem to have a "contingent contrary". This means that "there seems to be no alternative to it which is possible" (Stove 1991: 72). A statement, however, is "a necessary truth, if there is no possible alternative to it" (Stove 1991: 73). Hence, the existence of an external world is self-evident. Rand (1982: 33) concurs that "[t]he metaphysically given cannot be true or false, it simply is ...".

The question must also be asked "whether solipsism is logically possible" (Stove 1991: 73). Those who assert that it is logically possible, either interpret solipsism incorrectly, which means that it does not amount to solipsism, or their interpretations are "necessarily false" (Stove 1991: 73).

Furthermore, the question arises whether solipsism can be refuted, and if so, on which grounds? Is solipsism irrefutable? It seems clear though that if objects are mind dependent, one cannot validly argue that an external world exists (see Flew 1984: 330).

It seems evident that in order to avoid the fallacy of solipsism or the making of a category mistake, the existence of an independent reality must be implicitly or explicitly upheld, and the distinction between ontology and epistemology must be maintained as they clearly refer to different things. Contesting or challenging the forgoing might well entail fallacious reasoning. Trigg (1980: 95) cautions that whenever the distinction between a "knowing subject and what is known" is blurred, the "status of knowledge itself is in jeopardy". Furthermore, "[w]ithout objective reality, we can say nothing true, and without the possibility of truth and error, there can be no possibility of rational judgement. Without rationality men can have no freedom of choice" (Trigg 1980: 197). Granted that human reason and rationality are limited by nature, human beings to a greater or lesser extent are arguably capable of distinguishing between truth and error.

\section{The Importance of the Relationship between Ontology and Epistemology}

Upholding the distinction between ontology and epistemology, and the relationship between them clearly seems important for avoiding fallacious reasoning. The distinction demonstrates the difference between things, and the relationship indicates the connection or link between things. 
Furthermore, ontology and epistemology are closely related and the distinction between them should be upheld as all research commences with a researcher's conception of the world, which itself is influenced by the experience a researcher contributes to the research process (Grix 2002: 179). Research strategies are based on ontological assumptions. Such strategies implicitly or explicitly make various claims about the kinds of things that can or do exist, the relations between them and the conditions of their existence (Blaikie 2007: 13). The relationship between ontology and epistemology is arguably important for various other reasons.

The meaning of ontology and epistemology, and the directional and logical relationship between them must be understood to enhance criticism and constructive dialogue among students and scholars (Grix 2002: 175). Bates and Jenkins (2007: 56), as stated previously, do not agree with this view and argue that prescribing a directional relationship between ontology and epistemology undermines "reflexive learning and the development of critical analysis ...". The relationship between ontology and epistemology, however, is logical in nature and it is dubious whether indicating a logical relationship has the influence or power to inhibit critical thought.

It is apparent that logically social and political reality cannot control human thought. It can influence, motivate, shape and inspire human thought and ideas, but it is doubtful whether reality can determine human thought and ideas in any strong causal sense. However, traumatic experiences like surviving a holocaust or war can profoundly affect or shape a person's outlook on life. Reality consists of human made phenomena (for example, inventions, institutions, structures and policies) - the products of human thought, creativity and productivity. These are in principle subject to change by human beings, unlike the metaphysically or ontologically given. Hence, a relationship exists between that which exists (ontology) and what human beings can know (epistemology). Knowledge, a product, then entails a relationship between the world and human beings. This implies that the relationship between the observer or the researcher and the social and political world is reciprocal. Interaction takes place between the researcher and reality, as knowledge is neither acquired nor exists in a vacuum. The nature of the interaction arguably may be active or passive to a greater or lesser degree.

Researchers, moreover, must have a theory of ontology, whether it is explicitly acknowledged or implicitly held, as a presupposition of the researcher's theory of epistemology (Spencer 2000: 2). Furlong and Marsh (Marsh and Stoker 2010: 184) support a similar view and state that a researcher or social scientist's notion of ontology and epistemology, whether acknowledged or not, "shape the approach to theory and the methods" which they use. A researcher's ontological and epistemological orientation then influences the methodology adopted and a researcher must 
acknowledge their own ontological and epistemological assumptions (Furlong and Marsh in Marsh and Stoker 2010: 210).

Blaikie (2007: 14) concurs that ontological assumptions, although they may not be explicitly stated, implicitly guide research and the methods adopted. It is furthermore important to be aware of the ontological assumptions that inform scientific research and their consequences "for research practice and outcomes" (Blaikie 2007: 25). These assumptions are embedded in the research paradigms and research strategies employed by researchers, and "they can also influence the choice of research methods" (Blaikie 2007: 25). This common sense view is also supported by Hay (2007: 118) who asserts that "ontological assumptions inform epistemological assumptions" and "both inform methodological choices".

Ontological and epistemological assumptions then inform and impact on the research process. They are fundamental to all research, hence the importance of understanding them (Grix 2002: 176). Grix (2002: 177) further emphasises that "[o]ntology is the starting point of all research, after which one's epistemological and methodological positions logically follow". Once researchers and students understand that research is based on ontological and epistemological assumptions, and the logical connection between ontology, epistemology and methodology, they can grasp "the impact one's ontological position can have on what and how we decide to study" (Grix 2002: 179). Ontological and epistemological assumptions then influence the questions a researcher asks, how they are formulated and how they are answered (Grix 2002: 179).

Ontological and epistemological assumptions, methodology, methods and data sources, moreover, are directionally logically interrelated. Although a directional relationship exists between ontology, epistemology, methodology, methods and data sources, this does not mean that one element determines another. It does not mean, for example, that a positivist ontological position will automatically lead to the adoption of a positivist epistemological position. It is important to note that methods themselves are not coloured by ontological and epistemological assumptions and that the choice of methods depends on the research questions (Grix 2002: 180181).

It is, however, not possible to establish by means of empirical enquiry which ontological and epistemological assumptions are the most appropriate for a particular research question. Researchers adopt ontological and epistemological assumptions "partly as an act of faith in a particular view of the world" (Blaikie 2007: 25). However, their strengths and weaknesses are subject to debate (Blaikie 2007: 25). Ontological and epistemological assumptions, which are 
regarded as necessary conditions for knowledge, are also beyond empirical proof or verification and empirical refutation (see Grix 2002: 177; Monteiro and Ruby 2009: 7). They are accepted as self evident.

\section{Conclusion}

The meaning of ontology and epistemology is relatively unproblematic. The same does not apply to what can be classified as ontological and epistemological. The relationship between ontology and epistemology is contested by various scholars and views of science. There is disagreement among scholars on the directionality of the relationship. Even if it is argued that ontology logically precedes epistemology, epistemology is required to gain knowledge of ontology. Hence, the relationship between the observer, who may be a researcher or a scientist, or a philosopher, and the observed which encompasses the social and political world is reciprocal in the sense that knowledge neither exists nor is acquired in a vacuum. Interaction takes place between the observer and the observed, but the extent and nature of such interaction is subject to debate.

Nevertheless, ontological and epistemological assumptions arguably play a role in scientific research. To the extent that they do, the distinction and relationship between ontology and epistemology should be upheld to eliminate the possibility of fallacious reasoning. Issues of ontology and epistemology and epistemology must not be obscured, conflated or confused. Furthermore, the one is arguably not reducible to the other. Ontology and epistemology then concern different things and the distinction between them should be upheld to avoid confusion and fallacious reasoning, particularly the committing of a category mistake. Moreover, the denial of an independent reality raises the issue of the fallacy of solipsism. The existence of an independent reality, however, is an assumption which can neither be proved nor refuted. Care should be taken not to commit logical errors and fallacies, and not to misuse and abuse language when engaging in scientific research. The related practice of obfuscating arguments by using different terms and concepts, but giving them similar meanings tend to create uncertainty and confusion as to their meanings. This outcome is counterproductive and does not lead to an understanding of scientific debate and the research process. Clear thinking requires the clear and precise use of scientific terminology. Key terms and concepts must be defined and the meaning attributed to them by the definition must be clear, precise and unambiguous. The meaning must also be used consistently in the research project (see Sartori 1984). The implication of not giving due attention to the correct use of terms and concepts, upon which research in the social sciences depend seems clear. The research process, findings, and the integrity, validity and soundness of the scientific enterprise might be compromised. Furthermore, definitional clarity is 
not likely to be served by logical errors and fallacies, but these only serve to create confusion. The misuse and abuse of language is unlikely to enhance the quality of research in the social sciences.

Lastly, it is likely that the distinction and relationship between ontology and epistemology will continue to be a subject of debate in the social sciences. The debate is contentious and cannot merely be accepted at face value. If the views and positions of scholars and researchers are challenged, it is incumbent upon them to be able to substantiate or provide a justification of their chosen stance. 


\section{Bibliography}

Baggini, J. and Fosl, P.S. 2003. The philosopher's toolkit. A compendium of philosophical concepts and methods. Malden, MA (USA): Blackwell Publishing.

Bates, S.R. and Jenkins, L. 2007. 'Teaching and learning ontology and epistemology in political science.' Politics. 2007. Vol 27 (1). 55-63.

Bhasker, R. 1997. A realist theory of science. (2nd ed.) London: Verso.

Blaikie, N. 2007. Approaches to social enquiry. (2nd ed.) Cambridge (UK): Polity Press.

Bryman, A. 2001. Social research methods. Oxford: Oxford University Press.

Chernoff, F. 2007. Theory and metatheory in international relations. Concepts and contending accounts. New York: Palgrave Macmillan.

Crotty, M. 1998. The foundations of social research. London: Sage.

Flew, A. 1984. A dictionary of philosophy. London: Pan Books Ltd.

Furlong, P. and Marsh, D. 2010. 'A skin not a sweater: ontology and epistemology in political science.' In Marsh, D. and Stoker G. (eds.) 2010. Theory and methods in political science. (3rd ed.) Houndmills, Basingstoke, Hampshire: Palgrave Macmillan.

Grix, J. 2002. 'Introducing students to the generic terminology of social research.' Politics. 2002. Vol 22 (3). 175-186.

Gunnell, J.G. 2011. 'Social scientific inquiry and meta-theoretical fantasy: the case of international relations.' Review of international studies. 2011. 37. 1447-1469.

Hallowell, J.H. 1954. The moral foundation of democracy. The University of Chicago Press.

Hay, C. 2002. Political analysis. A critical introduction. Basingstoke: Palgrave.

Hay, C. 2007. 'Does ontology trump epistemology? Notes on the directional dependence of ontology and epistemology in political analysis.' Politics. 2007. Vol 27 (2). 115-118.

Jackson, P.T. 2008. 'Foregrounding ontology: dualism, monism, and IR theory.' Review of international studies. 2008. 34. 129-153.

Lunn, A. 1950. The revolt against reason. London: Eyre and Spottiswoode.

Marsh, D. and Stoker, G. (eds.) 2010. Theory and methods in political science. (3rd ed.) Houndmills, Basingstoke, Hampshire: Palgrave Macmillan.

Monteiro, N.P. and Ruby, K.G. 2009. 'IR and the false promise of philosophical foundations.' International theory. 2009. 1. Cambridge University Press.

Moses, J.W. and Knutsen, T.L. 2007. Ways of knowing. Competing methodologies in social and political research. Houndmills, Basingstoke, Hampshire: Palgrave Macmillan. 
Mounce, H.O. 1977. 'Philosophy, solipsism and thought.' The philosophical quarterly. 1977. Vol 47. No 186. 1-18. http://www.jstor.org/stable/2956468. Accessed 08.03.2012.

Neale, J.M. and Liebert, R.M. 1986. Science and behaviour. An introduction to methods of research. (3rd ed.) Englewood Cliffs, New Jersey: Prentice-Hall, Inc.

Rand, A. 1961. For the new intellectual. New York: Signet.

Rand, A. 1982. Philosophy: who needs it. Indianapolis, New York: The Bobbs-Merril Company, Inc.

Rawnsley, M.M. 1998. 'Ontology, epistemology, and methodology. A clarification.' Nursing science quarterly. 1998. 11. 2. Sage. http://www.sagepublications.com) http://nsq.sagepub.com/content/11/1/2. Accessed 16.02.2012.

Ryle, G. 1988. The concept of mind. London: Penguin Books.

Sartori, G. (ed.) 1984. Social science concepts. A systematic analysis. London: Sage.

Spencer, N. 2000. 'On the significance of distinguishing ontology and epistemology.' http://www.ethicalpolitics.org/seminars/neville.htm. Accessed 25.05.2012.

Stove, D. 1991. The Plato cult and other philosophical follies. Oxford (UK): Basil Blackwell.

Trigg, R. 1980. Reality at risk. A defence of realism in philosophy and the sciences. Sussex: The Harvester Press.

Trigg, R. 1985. Understanding social science. A philosophical introduction to the social sciences. Oxford (UK): Basil Blackwell.

Trigg, R. 2002. Philosophy matters. Malden, MA (USA): Blackwell Publishers. 